\title{
Kabbalah Logic and Semantic Foundations for a Postmodern Fuzzy Set and Fuzzy Logic Theory
}

\author{
Gabriel Burstein, Constantin Virgil Negoita, Menachem Kranz \\ Department of Computer Science, Hunter College, City University of New York, New York, USA \\ Email: burstein.gabriel@gmail.com
}

Received 27 March 2014; revised 27 April 2014; accepted 4 May 2014

Copyright (C) 2014 by authors and Scientific Research Publishing Inc.

This work is licensed under the Creative Commons Attribution International License (CC BY). http://creativecommons.org/licenses/by/4.0/

(c) (i) Open Access

\section{Abstract}

Despite half a century of fuzzy sets and fuzzy logic progress, as fuzzy sets address complex and uncertain information through the lens of human knowledge and subjectivity, more progress is needed in the semantics of fuzzy sets and in exploring the multi-modal aspect of fuzzy logic due to the different cognitive, emotional and behavioral angles of assessing truth. We lay here the foundations of a postmodern fuzzy set and fuzzy logic theory addressing these issues by deconstructing fuzzy truth values and fuzzy set membership functions to re-capture the human knowledge and subjectivity structure in membership function evaluations. We formulate a fractal multi-modal logic of Kabbalah which integrates the cognitive, emotional and behavioral levels of humanistic systems into epistemic and modal, deontic and doxastic and dynamic multi-modal logic. This is done by creating a fractal multi-modal Kabbalah possible worlds semantic frame of Kripke model type. The Kabbalah possible worlds semantic frame integrates together both the multi-modal logic aspects and their Kripke possible worlds model. We will not focus here on modal operators and axiom sets. We constructively define a fractal multi-modal Kabbalistic L-fuzzy set as the central concept of the postmodern fuzzy set theory based on Kabbalah logic and semantics.

\section{Keywords}

L-Fuzzy Sets, Fuzzy Sets, Fuzzy Logic, Modal Logic, Fuzzy Semantics, Kripke Possible Worlds Model, Kabbalah, Sefirot, Partzufim, Tree of Life, Tikkun, Postmodernism, Deconstruction, Logic, Humanistic Systems

\section{Fuzzy Sets Half a Century after Zadeh's Seminal Paper: What Is Still Missing?}

Next year it will be exactly 50 years, half a century that is (!), since Zadeh's seminal 1965 paper [1] that trig- 
gered a true "fuzzy sets and fuzzy logic revolution" in thinking, theory and applications. The progress and achievements are undoubtable in number of papers, researchers focusing on this, results, applications, books and journals devoted to this topic. In fact, in 2015 it will also be exactly 40 years since the first published fuzzy sets monograph in the field by Negoita and Ralescu in 1975 [2]. However, fuzzy sets and fuzzy logic have not yet achieved universal acceptance like its predecessor Boolean logic and classical set theory. Some of it is normally due to clashes between different schools of mathematical thinking, some of it is due to resistance to a fundamental innovation but there are in our view also fundamental objective reasons for this and addressing them may also be, perhaps, a source of renewed progress and development in fuzzy set theory:

1) Fuzzy sets theory does not have an objective framework and constructive methodology for describing and incorporating human subjectivity and behavior in assessing complex knowledge into the fuzzy membership function construction. Fuzzy sets and fuzzy logic are, among other things, about including human subjectivity and approximate reasoning nature in a mathematical theory of complex and uncertain information.

2) There is more work to do on the semantics and philosophical logic foundations of fuzzy sets and the multimodal aspects of fuzzy logic. For a start, truth values are more than just numbers and Goguen's L-fuzzy set theory [3] addressed that by proposing a general lattice L instead of [0.1]. Zadeh’s, Dubois and Prade's and others Possibility Theory [4] and the modal logic approach to fuzzy semantics in [5]-[7] speak for acknowledging this need for the meaning of truth. Modal logic was developed to better capture the many facets of truth and its application to build a hierarchical meta-theory of fuzzy sets is a promising path that needs to be continued. Fuzzy sets and fuzzy logic are missing an integrative semantic structural framework reflecting the complex human nature and subjectivity trying to assess complex knowledge that fuzzy sets and fuzzy logic are meant to represent.

We will attempt here to follow a postmodern approach [8] to go back and deconstruct fuzzy sets, membership functions and truth values in order to give them more structure and connect them to the human cognitive, emotional and behavioral aspects in assessing complex information that originated the need for fuzzy sets and logic.

As most postmodern approaches are finding sources of inspiration and real tools in pre-modern ancient theories and philosophies, we too will show that the ancient analytical philosophy of Kabbalah [9]-[11] offers an ideal structural framework to address 1) and 2). Kabbalah formulated a unique integrative fractal structure of human knowledge, emotions and behavior. We will show that long before the emergence of modern fuzzy set theory and logic, Kabbalah discovered and implemented the need for a multiple valued modal logic in the context of describing creation and creatures, human subjectivity and behavior.

Our objective in this paper is to formulate here for the first time a fractal, multiple valued modal logic of Kabbalah and to use it as a framework for a postmodern fuzzy set and fuzzy logic theory based on a fractal Kabbalah semantic frame incorporating human subjectivity and behavior in order to address 1), 2) above.

\section{The Sefirotic Tree of Life of Kabbalah as a General Structural Framework}

According to Kabbalah, the structure of human existence, with its cognitive, emotional and behavioral aspects, has a set S of ten fundamental general components/properties/attributes called "sefirot" (counts or units in Hebrew, sefira singular, sefirot plural), grouped in the Sefirotic Tree of Life (T) which is a graph with S, the node set, and edges representing a specific binary relation between sefirot as a subset of $\mathrm{S} \times \mathrm{S}$. T has three triadic levels [9]-[11]:

1) Knowledge and cognitive level: Sefirot Wisdom (Chochmah in Hebrew), Understanding (Binah) and Knowledge (Da'at) which in fact prepares the transition and implementation of understanding at the emotional level. There is also Sefira Crown or Keter (standing for desire, will) at this level but it is customary not to represent Crown and Knowledge together and to use a simplified representation with either of them so we will use sefira Knowledge only. This first level forms a triad $\mathrm{ChaBaD}$, from the initials of the three sefirot which we will denote by CBD.

2) Emotional level: Sefirot Loving kindness (Chesed), Judgment/Justice/Strength/Rigor or Severity (Gevurah) and Harmony or Beauty (Tiferet) which is connected to the next level below. These three sefirot form the triad Cha GaT that we will denote by C'GT where C' is used for sefira Chesed.

3) Behavioral and physical action level: Sefirot Perseverance or Endurance (Netzach), Victory or Majesty (Hod), Foundation (Yesod) and Kingship (Malchut). We will omit as it is customary sefira Kingship (Malchut) and use a simplified representation in which Yesod and Malchut are viewed together. The triadic level for behavior and physical actions will be denoted by NHY. 
Despite their metaphorical anthropomorphic names, these nine fundamental attributes or components of human existence (represented by the nine sefirot selected above in a simplified representation), represent a very general, metaphoric coordinate system of 9 general basic attributes or properties that can be used to describe complex humanistic systems in general just like the Cartesian system $X, Y, Z$ is used for physics.

The internal sub-structure of each sefira is again of the type of a Tree of Life made of 10 sub-sefirot (or 9 subsefirot in our simplified representation) of the same type as the original 9 sefirot. Just like sefirot are interconnected, sub-sefirot of sefirot are interconnected with each other: "Hitkashrut" is the interconnection linking every sub-sefirot $S(i)$ of sefirot $S(j)$ to the sub-sefirot $S(j)$ of sefirot $S(i)$, for all $i$ different from $j$ running from 1 to 9. So Wisdom of Understanding is interlinked with Understanding of Wisdom. This way, each sefira $S(i)$ is linked to all sefirot $S(i)$ of $S(j)$ for all $j=1, \cdots, 9$. The Sefirotic Tree of Life has a fractal, self-similar structure, see Figure 1. In principle, we can go on and speak of the sub-sub-structure of sub-sefirot which will also be in the shape of a sub-Tree of Life etc. However, while we will emphasize here the full fractal structure, we will only go up to the second order sub-structure of the Tree of Life.

Not only has the Tree of Life three hierarchical levels described here on the vertical but it also has three axes as we move from Right to Left horizontally: the Right axis is the axis of Chesed, Loving kindness and it stands for giving, accepting, masculine side, being active; the Left axis is the axis of Judgment (Gevurah) and it stands for rigor, discipline, feminine side, being passive; the Middle axis is the axis of Mercy and Harmony (Rahamim) and it stands for harmony and middle line compromise, balance etc.

The Tree of Life can also be seen in terms of configurations of sefirot (or partzuf, singular, or partzufim, plural in Hebrew, Aramaic) structured around the main sefirot in the Tree of Life [9] [10]. The partzuf is a more complex form of organization of sefirot. We will use here a simplified representation of the Tree of Life in terms of partzufim, configurations of Sefirot, including only the partzufim of Wisdom (called the Father or Aba in Hebrew, organized around Sefira Wisdom), Understanding (called Mother or Imah in Hebrew, organized around sefira Understanding), Small Configuration (called Zeir Anpin (ZA) in Hebrew, organized around sefira Harmony using sefirot Loving kindness, Judgment, Perseverance, Majesty and Foundation) and Kingship Configuration (called Female or Nukva (Nu) in Hebrew) (see Figure 2). Configurations of sefirot or partzufim, although

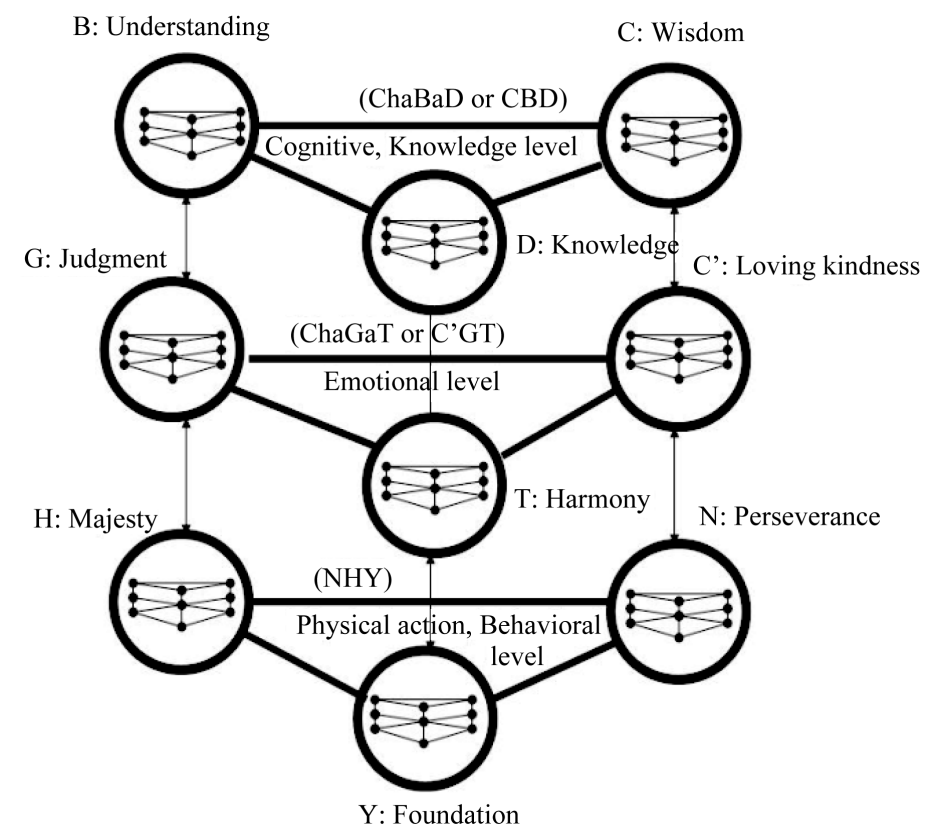

Figure 1. The fractal Tree of Life of Sefirot of Kabbalah (simplified representation) with 9 interconnected sefirot organized in three interconnected vertical structural levels corresponding to the cognitive, emotional and behavioral levels of humanistic systems. It can be used as a multidimensional coordinate system to map the structure of any object, set, system. 


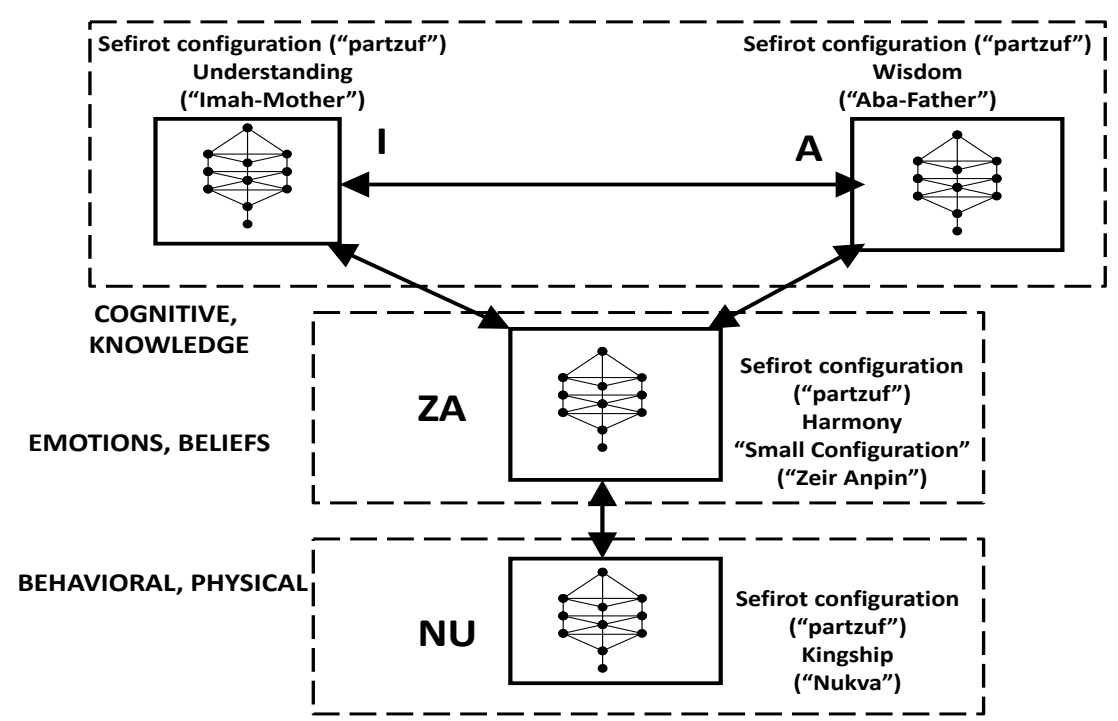

Figure 2. The Tree of Life of Partzufim of Kabbalah structured as a set of interconnected configurations of sefirot (partzufim in Hebrew). Partzufim Wisdom and Understanding make up the cognitive level. Partzuf Small Configuration (ZA) represents the emotional level and Partzuf Kingship represents the behavioral, physical action level. For simplicity, we did not represent here the partzuf of Keter.

organized around a main sefira or attribute, ultimately contain each their own ten sub-sefirot (or nine sub-sefirot in our simplified triadic representation).

The configurations of Wisdom and Understanding form the Cognitive level of the Tree of Life. This is a simplified representation, an approximation. We have left out many other important configurations or partzufim such as the Partzuf Crown or Keter which is one of the most important partzufim and which normally is part of the Cognitive level of the Tree of Sefirot together with Configurations Understanding and Wisdom. Configuration Harmony or Small Configuration (ZA) is the emotional level and Configuration Kingship (Nu) is the behavioral, physical action level.

\section{The Logic of Kabbalah: Construction and Deconstruction of the Tree of Life of Sefirotic Configurations}

In Kabbalah, there is a very precise construction process (Tikkun) of the Tree of Life of Partzufim in Figure 2 using two basic opposite but complementary Trees of Life of Sefirot which are each in a linear form, with each Sefira below the previous one [8] and not like in Figure 2 with sefirot along three parallel axes.

Each of these two initial Trees, represent one of the two opposite yet complementary fundamental principles, natures, essences or views of human existence and reality in Kabbalah: Mah, denoted by $M$ (standing for kindness, acceptance, masculine side, being active, "is like") and Ban, denoted by $b$ (standing for rigor, discipline, judgment, rejection, feminine side, being passive, "is not like"). The construction process Tikkun (repair or correction in Hebrew) corrects the initial incomplete Ban linear sefirotic tree structure into a combined Ban and Mah arrangement of interconnected configurations of linked sefirot (partzufim), along three vertical axes that complement each other [9] [10].

In Kabbalah, Mah is considered to be of a "higher", "greater" level than Ban, a "better" type yet both are required and complementary to each other. In general, sefirot and partzufim on the right side and top triadic level of the Sefirotic Tree are of Mah type while sefirot on the left side and lower triadic levels are of Ban type. As we saw, everything in Kabbalah is organized in a fractal, self-similar way as we move from one level of organization to the next one. The sefirot of the Tree of Sefirot Ban (denoted by $T(B a n)$ ) and those of the Tree of Sefirot Mah (denoted by $T($ Mah)) are each also of two sub-types: Ban type sefirotor Mah type sefirot. So too the sub-sefirot of each of these sefirot are of Ban or Mah sub-sub-type. From Tree to sefirot and to sub-sefirot, each level has one of these two logical or modal or type values, Mah or Ban. For example, sub-sefira Understanding of the sefira Wisdom of the Tree of Sefirot Mah is of type Ban of Mah of Mah, denoted "bMM" since sefira 
Wisdom is of Mah type and Understanding is of Ban type.

Since we have two fundamentally opposed but complementary types, Ban and Mah and three fractal levels of organization (Tree, sefirot, sub-sefirot) which can be each of Ban or Mah type, we will have a set, denoted by $L$, of 8 different triplet combinations of types or 8 truth values:

$$
L=\{b, M\} \times\{b, M\} \times\{b, M\}=\{b b b, M b b, b b M, b M b, M M b, b M M, M b M, M M M\}
$$

Mah is of "higher", more complete type than Ban so we can define a total order relation " $b \leq M$ " on each of the sets $\{b, M\}$ (we use non-strict inequality sign and allow $b \leq b$ and $M \leq M$ by definition). That means that we can give $\mathrm{L}$ a partial and/or a total ordered set structure by defining two possible order relations. The most obvious total order relation would be an inverse lexicographic relation between triplets of $\mathrm{L}$ ordered like words made of $M, b$ letters in a dictionary with letter $M$ being ranked first ahead of $\mathrm{b}$ and reading the words from right to left when ranking them: for example $M b b \leq M b M$ etc. (we will use same notation " $\leq$ " for order relation on $L$ ). The problem with this order relation is that the specific Kabbalistic interlinking of sefirot "Hitkashrut", discussed in Section 2, establishes a sort of "functional equivalence" relation according to which for example $M$ of $b$ of $M(M b M)$ is equivalent in this sense with $M$ of $M$ of $b$ (because $M$ of $b$ and $b$ of $M$ are interlinked through "Hitkashrut"). This would contradict $M M b \leq M b M$ according to the inverse lexicographic order relation described above. The second order relation between the triplets of $L$ is obtained as the Cartesian product naturally induced order on $L$ (seen as a multiple Cartesian product as above): $X Y Z \leq X^{\prime} Y^{\prime} Z^{\prime}$ if $X \leq X^{\prime}$ and $Y \leq Y^{\prime}$ and $Z \leq Z^{\prime}$. $(L, \leq)$ can be endowed with two operations between two arbitrary elements $a, b$ of $L: a \wedge b$ (greatest lower boundor "inf" of $a, b$ in $L$ relative to $\leq$ called "meet") and a $\vee$ b (least upper bound or "sup" called "join"). ( $L, \leq$, $\Lambda, \vee)$ is a special type of poset with this partial order relation and operations: it is a lattice with all the good properties required in L-fuzzy sets theory (distributive, complete etc.) [3] in order to define operations with fuzzy membership functions taking values in $L$ for L-fuzzy sets operations (L-fuzzy sets are fuzzy sets with membership functions taking values in a lattice $L$ ). Our Kabbalah based lattice $L$ has 8 elements that can be represented in Figure 3 by a Hasse lattice diagram looking like a cube corresponding to the partial order $\leq$. If we continue the above fractal process of Kabbalah we can create lattices $L$ having higher and higher numbers of elements, increasing like $2^{\mathrm{N}}$ which makes $L$ not only good for multiple-valued logic but also for infinite-valued and continuum-valued logic approximation hence good for fuzzy sets.

Based on all these, we can represent the construction (Tikkun) of the Tree of Sefirotic Configurations (Partzufim) in Figure 3. We see how the Tree of Sefirotic Configurations, $T$ (Ban, Mah), of a mixed Ban and Mah type
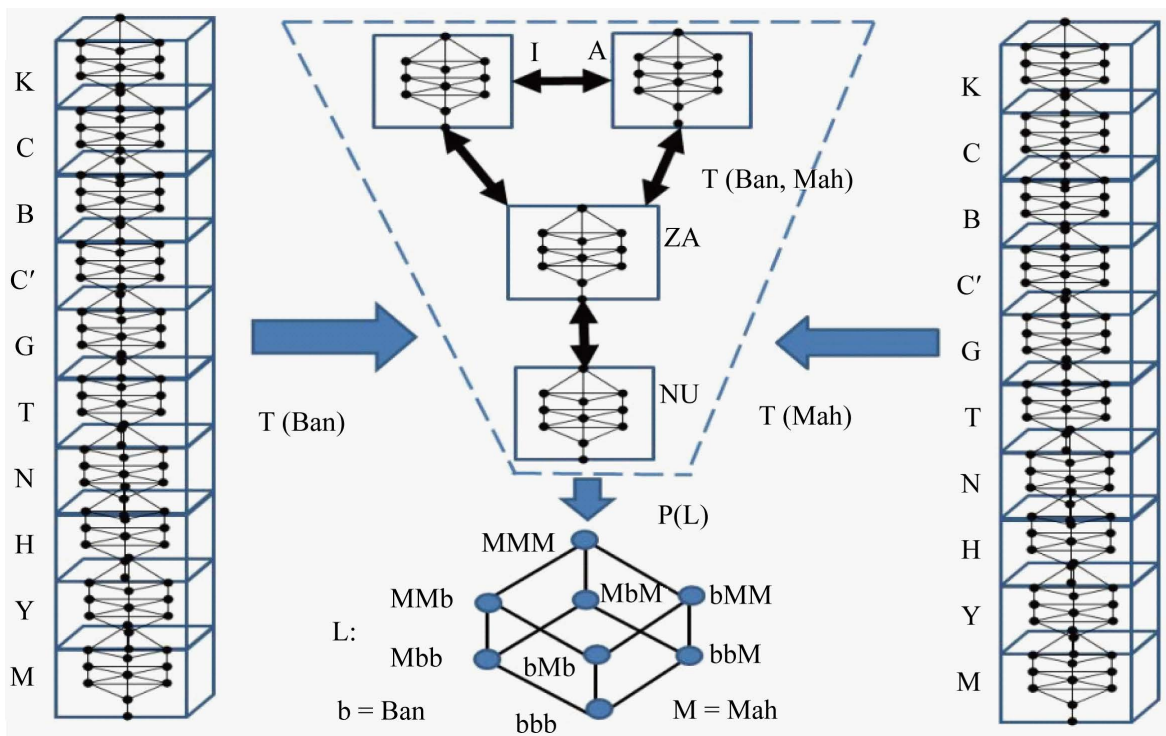

Figure 3. The fractal multiple valued logic of Kabbalah: construction (Tikkun) of the Tree of Sefirotic Configurations (partzufim) T(Ban, Mah) out of the linear Trees of Sefirot of Ban and of Mah. The logic of Kabbalah is based on the lattice $L$ (and its powerset $P(L)$ ) of $2^{3}=8$ truth values given by third order combinations of Mah and Ban. $L$ can be generalized for $2^{\mathrm{N}}$. 
is being built out of the linear Tree of Sefirot of Ban, $T(\operatorname{Ban})$, and the Tree of Sefirotof Mah, $T($ Mah). The sefirotic configurations of $T(\mathrm{Ban}, \mathrm{Mah})$ are each made of several sub-sefirot of sefirotof $T$ (Ban) and $T$ (Mah) [10] which can each be a signed any of the 8 types of third order combinations of Mah and Ban shown in lattice L defined earlier. Hence, the partzufim (configuration) can be each assigned a subset of $L$. The set of all subsets of L forms the power set of $L$, denoted by $P(L)$.

If we take Ban interpreted as rejection or what something "is not like" and Mah interpreted as acceptance or what something "is like" we have one possible preliminary set theoretic and logical interpretation of the many possible modal logic interpretations of Tikkun as a Kabbalah logic model of how multiple-valued logic and fuzziness appear naturally by aggregating, blending two classical two-valued Boolean logic complementary fractal views of the cognitive, emotional and behavioral levels. We identified, formulated and represented here this logical process in order to unveil the multiple valued fractal logic nature of Kabbalah and to use it as a logic reverse engineering tool to deconstruct fuzziness in the spirit of postmodernism as explained in [8].

\section{The Fractal Modal Logic of Kabbalah as a Structural Framework for a Postmodern Fuzzy Set and Fuzzy Logic Theory}

The three levels of the Tree of Sefirot in Figure 1, 1) CBD (Cognitive, knowledge level), 2) C'GT (Emotional, beliefs and values level) and 3) NHY (Behavioral, physical action level)are an ideal hierarchical model for human subjectivity, knowledge and behavior and can be used to qualify truth of any fuzzy statement (proposition) based on fuzzy concepts. These three levels correspond to three important categories of modal logic [12] which qualify truth from the various points of view of the assessing human subject: 1) Epistemic and modal, 2) Doxastic and Deontic and 3) Dynamic logic of Action. We will use here the term "modal logic" (or multi-modal logic) to refer collectively to all types of logic enumerated above of which modal logic was initially a particular type. Historically, modal logic was about assessing the possibility and necessity modes or facets of truth only but more and more modal logic is used as a generic name for all other modes of logic truth assessment.

Epistemic and modal logic aspect of truth is about cognition and knowledge and about assessing possibility and necessity of truth (it is known that, it is possible that, it is necessary that). Doxastic and Deontic modal logics deal with beliefs, value systems and permissibility or non-permissibility in assessing truth (it is believed, it is permissible). The dynamic logic of action aspect of truth is about the feasibility and temporal sequencing of our behavior and physical actions. Zadeh, Dubois, Prade and others have the merit to have connected the possibility and necessity modal logic with fuzzy logic in the possibility theory [4] but only later were fuzzy semantic models for fuzzy modal logic created to fundament the modal logic approach to fuzzy logic [5]-[7].

When trying to assess the truth about something, we can look at it based on our knowledge at cognitive level, we can look at it based on our emotionally shaped beliefs and system of values or we can look at it from a physical action and behavioral feasibility point of view in time [4] [12]. These different assessments of truth are also inter-dependent and the interconnected triadic levels of the Tree of Sefirot are a perfect model for this multimodal logic [13]. Beliefs of the doxastic modal aspect of truth are subjective emotional reflections on acquired knowledge and perceptions formed at the epistemic modal level. Postmodern truth is fragmented not only in multiple truth values but in the multiple levels or angles of looking at it which naturally leads to multiple truth values.

Looking at Figure 1 in terms of the fractal structure of these levels, we see that each level has its own three sub-levels made of the sub-sefirot of each sefirot. We can represent this equivalently in a simplified way as the cube in Figure 4 where the three horizontal levels represent the three basic modal logic aspects of truth (epistemic and modal, doxastic and deontic, dynamic logic of action) listed above and each such modal level can be in its turn decomposed into its own three fractal sefirotic sub-levels (cognitive, emotional, behavioral) linked to human subjectivity, behavior and knowledge. This fractal modal logic cube representation in Figure 4 is based on applying our fractal modal logic structure of truth highlighted above to the Kabbalah cube representation of the Sefirotic Tree of Life of Schatz [13].

We see in Figure 4 for example, the CBD, C'GT, NHY horizontal layers of “sub-cubes”. Each layer has its own three segments which appear at the intersection of the horizontal layers CBD, C'GT, NHY with the vertical layers of CBD, C'GT, NHY. This way each of the 27 sub-cubes is very precisely identified and can be attributed a Ban-Mah derived relative type based on the right side being assigned Mah type (Tree of Mah Sefirot in Figure 3 is on the right side of the Tree of Life of Mah and Ban). Left side of the cube in Figure 4 is assigned Ban type as the Tree of Ban Sefirot is on the left side of the Tree of Life in Figure 3. Top cognitive intellectual CBD level is 


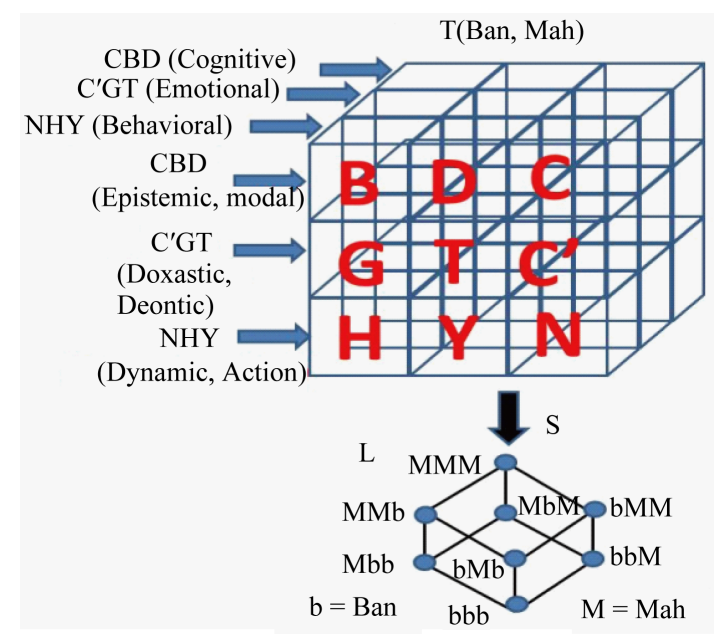

Figure 4. The fractal multi-modal logic representation of the Sefirotic Tree of Kabbalah as a cube of sefirot and triads and the Mah-Ban type weighting function S assigning to each of the 27 sub-cubes (sub-sefirot) their Mah-Ban type in a lattice $L$ of $2^{3}=8$ Mah-Ban third order combinations represented by a Hasse lattice diagram. $\mathrm{L}$ can be generalized for $2^{\mathrm{N}}$ logical truth values.

of Mah higher type than the emotional, behavioral C'GT and NHY levels which are of Ban types. The vertical middle column DTY is of mixed Ban-Mah type and splits in two sub-columns [13], one of Ban and one of Mah type. For simplicity, we have omitted here this detail which can be added for a correct full picture representation in Figure 4.

For example, in the cube of Figure 4, the front-top-right sub-cube is the Wisdom C (Chochmah) sub-cube of the CBD horizontal layer of the vertical NHY layer so it is the C of CBD of NHY. Based on CBD being of "higher" Mah type and NHY being of "lower" Ban type, C of CBD of NHY sub-cube is of Mah-Mah-Ban (MMb) type. The cube can also be seen equivalently as having three vertical columns of sub/cubes at the front CC'N, DTY, BGH. The precise Ban-Mah type assignment is based on the Tikkun construction details in Figure 3. The modal logic interpretation of partzufim identifies partzufim A and I in Figure 3 with the epistemic and modal logic level, partzuf ZA is the doxastic, deontic logic level and partzuf Nu represents the dynamic logic of action level.

\section{Kabbalistic L-Fuzzy Sets Based on Modal Kabbalistic Semantics for Fuzzy Logic}

L-fuzzy sets introduced in [3] had the early merit of looking for more general models of fuzzy truth rather than $[0,1]$ interval and a complete distributive lattice is such a general model satisfying the minimal requirements of human subjectivity in action to assess fuzziness: 1) we must be able to order and compare elements and 2) we can find the least upper bound and the greatest lower bound for pairs of elements and sets in $L$ in order to define L-fuzzy set operations.

We will give here a constructive definition of a Kabbalistic L-fuzzy set, offering a modal logic and fractal structural incorporation of human knowledge, subjectivity and behavior in the existing modern L-fuzzy sets definition [3].

We introduce first the Kripke possible worlds model for modal logic [5] [6] [13] to be a triple $M=<W, R$, $V, S>. W$ is a set of "possible $N$ worlds" $W=\{W(1), \cdots, W(N)\}$ (meaning in our context possible angles or points of view, levels or types of approach, facets of looking at the truth of a logical proposition, statement, predicate related to a complex, fuzzy concept [14]). $R$ is a binary relation between the worlds $W$, called "accessibility relation" given by a subset of $W \times W$ according to which $W(i) R W(j)$ means $W(j)$ is accessible to $W(i)$. $<W, R>$ is called a Kripke frame of possible worlds. $S$ is a weighting function assigning weights to each possible world which will be defined later. $V$ is a valuation function of the truth of simple (atomic) propositions $P(x, A) \in$ Prop, the set of atomic propositions: 


$$
\begin{aligned}
& P(x, A)=\langle x \text { belongs to } A\rangle \text {, for } x \text { in } X \\
& V: \text { Prop } \times W \rightarrow\{0,1\} \text { (or more general } V: \text { Prop } \times W \rightarrow L) \\
& V(P(x, A), W(i))=1(\text { true) or } 0(\text { false) for each } i=1, \cdots, N \text { and } x \text { in } X
\end{aligned}
$$

Here A is a fuzzy subset describing a "fuzzy concept" [14] taking values in a universe of discourse $X$ (e.g. $A=$ "tall men", $X=$ "men"; $A=$ "smart people", $X=$ "people"; $A=$ "beautiful women", $X=$ "women"). The fuzzy concept $A$, as a fuzzy subset of $X$, is described by its membership function $\mathrm{m}(A, x)$ :

$$
m(A, \cdot): X \rightarrow[0,1](\text { or more general } m(A, \cdot): X \rightarrow L \text { for a lattice } L[3])
$$

The set of fuzzy concepts taking values in a universe of discourse $X$ is a subset of $L^{X}=\{$ functions $f: X \rightarrow L$. $V$ can thus be thought of as $V: L^{X} \times W \rightarrow L$ that is, as a "Kripke possible worlds model for L-fuzzy sets". In our case, we will consider the frame $<W, R>$ defined by the graph in Figure 5 where sefirot represent the "worlds" and the binary relation of "accessibility" between the "possible worlds" is represented by the edges between sefirot. We will denote this Kripke frame by $T(\mathrm{Ban}, \mathrm{Mah})=\langle W, R\rangle$ since it represents the triadic structure of the Tree of Life. Figure 5 shows the inter-connections behind the simplified cube structure in Figure 4 and behind the fractal structure in Figure 1. Each sefirot or sub-cube represents a certain point of view, a "world" from which truth is assessed based on the attribute type of that sefirot (cognitive, emotional, behavioral) and the modal logic level that sefirot belongs to (epistemic or modal, doxastic or deontic, dynamic logic of action or temporal).

The edges of triangles in Figure 5 represent the CBD, C'GT, NHY sefirotic levels and their sub-levels (like in Figure 1), the vertical edges in Figure 5 represent connections between triadic levels in the Tree of Life (like in Figure 1), the horizontal longitudinal edges in 3D perspective in Figure 5 represent connections between sub-triadic levels and the diagonal edges represent the "hitkashrut" (Hebrew) interconnections between sub-triadic levels which link for example CBD of NHY with NHY of CBD, C'GT of NHY with NHY of C'GT and so on. The "hitkashrut" interconnection between sub-sefirot explained in Section 2, induces the similar "hitkashrut" interconnection between the sub-triadic levels of sefirot which was discussed here.

One of the advantages of our Kabbalah semantic frame proposed in Figure 5 is that it integrates in one structure the semantics and the modal logic operators. The sefirot through their fractal sub-sefirot structure play a dual role: they are both implicit modal operators and possible worlds. Normally in modal logic [12], one defines the modal operators such as " $P=$ it is possible", " $N=$ it is necessary", " $K=$ it is known", " $B=$ it

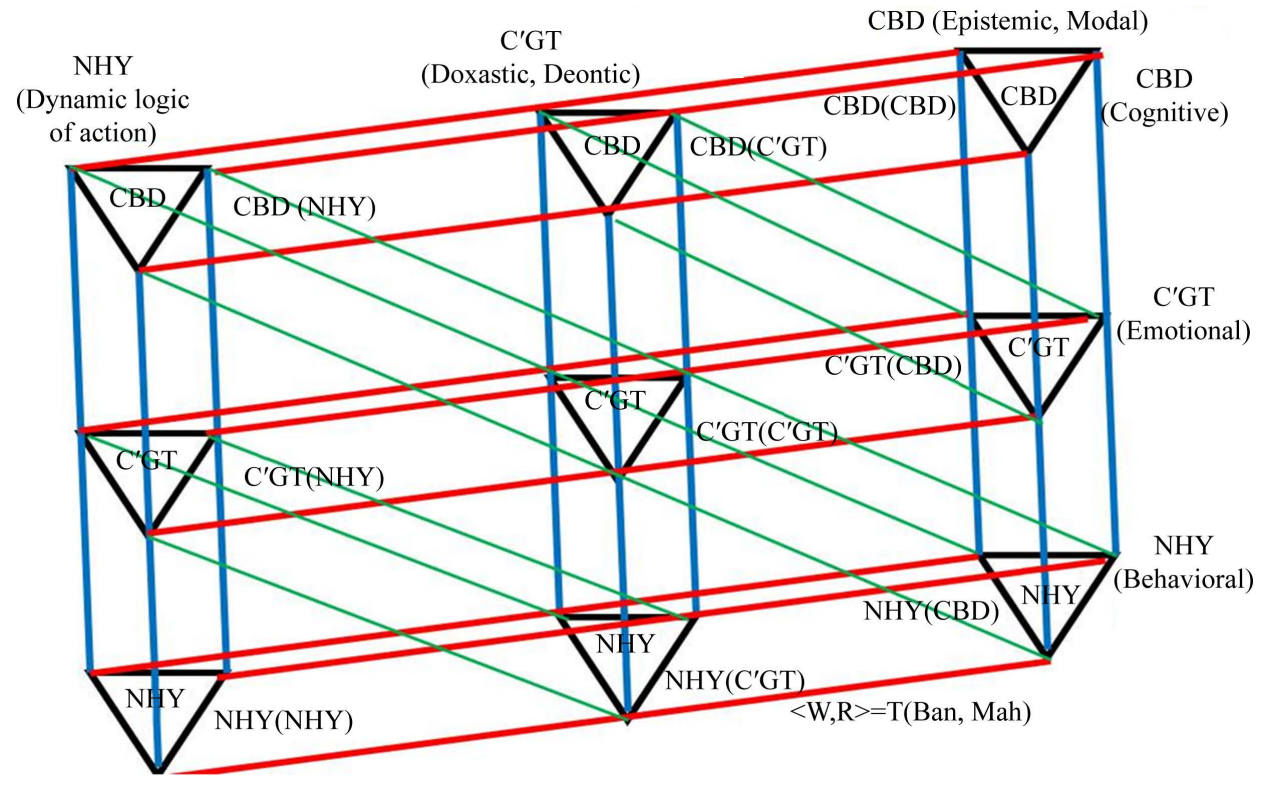

Figure 5. A Kabbalah fractal semantic frame $<W, R>=T$ (Mah, Ban) for fuzzy modal logic based on Kripke possible world semantics where $W$ are the "possible worlds" represented by the sefirot and the lines give the graph of the accessibility relation between worlds $W$. 
is believed" etc. acting on the propositional language $<$ Prop $>$ (propositional calculus) generated by the atomic propositions Prop and then one builds a Kripke semantics of possible worlds to assess the truth for the modal logic.

The proposed Kabbalah semantic possible worlds frame $T$ (Ban, Mah) integrates multi-modal logic levels and their Kripke semantic models (cognitive, emotional and behavioral) in a fractal way. Although we generically referred to $R$ as an accessibility relation, the relation between sefirot displayed by the Tree of Life as a graph is multi-modal given its three levels. This allows the deconstruction of the logic truth valuation at various modal logic levels and their semantic sub-levels using $V$ : Prop $\times W \rightarrow L$ as follows:

$$
\begin{aligned}
& \{V(P(x, A), W), W \in \boldsymbol{C B D}\} \text { are the epistemic or modal truth valuations } \\
& \left\{V(P(x, A), W), W \in \boldsymbol{C}^{\prime} \boldsymbol{G} \boldsymbol{T}\right\} \text { are the deontic or doxastic truth valuation } \\
& \{V(P(x, A), W), W \in \mathbf{N H} Y\} \text { are the dynamic logic truth valuation }
\end{aligned}
$$

At each of the three modal logic levels above, the truth is assessed from the cognitive (CBD), emotional (C’GT) and behavioral (NHY) perspective levels of the Tree of Life (see Figure 4, Figure 5). These hierarchically and feedback inter-linked levels provide an ideal model for axioms inter-linking modal logic operators. For example, $K$ (is known) and $B$ (is believed) are inter-linked by "what is believed is known" and "what is known is believed" just like CBD (cognitive, knowledge) and C'GT (beliefs, emotions) are hierarchically (top-down) and feedback (bottom-up) inter-linked in the Tree of Life.

The idea behind using Kripke possible worlds model to construct the fuzzy membership function $m(A, x)$ used in [5] [6] is to average the truth or false, 0 or 1 simple answer of the valuation function $V(P(x, A), W(i))$ across all possible worlds $W(i)$. For this we need also a weighting function $S: W \rightarrow L$ of the possible worlds. Our possible worlds frame is $\langle W, R\rangle=T$ (Ban, Mah), defined in detail in Figure 5 and represented in the simplified cube form in Figure 4. $S$ is the L-valued possible world weighting function shown in Figure 5:

$$
S: T(\text { Ban, Mah }) \rightarrow L, \quad W=T(\text { Ban, Mah })
$$

$S$ assigns an element of the lattice $L$ of 8 Mah-Ban third order combinations (displayed in the Hasse lattice diagram of $L$ in Figure 4) to each of the 27 sub-cubes (sefirot) from the cube representation of the Sefirotic Tree of Life $T$ (Ban, Mah) in Figure 4. These cubes correspond to the 27 possible world's sefirot in Figure 5. $S$ gives the Ban-Mah weighting degree of relevance for each of the possible worlds.

We define the membership function of a Kabbalistic L-fuzzy set (L-fuzzy subset of $X$ corresponding to fuzzy concept $A), m(A, x)$, taking values in the lattice of 8 Ban-Mah types:

$$
\begin{aligned}
& m(A, \cdot): X \rightarrow L, \quad V: \text { Prop } \times W \rightarrow L \\
& m(A, x)=\vee\{[V(P(x, A), W(i)) \wedge S(W(i))] \text { for all } i=1, \cdots, 27\}
\end{aligned}
$$

For $V: \boldsymbol{P r o p} \times W \rightarrow\{0,1\}$ we have $m(A, x)=\vee\{[S(W(j))]$ for all $j$ for which $V(P(x, A), W(j))=1\}$.

We can deconstruct the L-fuzzy set membership function at various modal logic levels and their semantic sub-levels using either the Kabbalah semantic frame in Figure 5 or the cube representation of Figure 4:

$$
\begin{gathered}
m(A, x)=m(A, x \mid \boldsymbol{C B D}) \vee m\left(A, x \mid \boldsymbol{C}^{\prime} \boldsymbol{G T}\right) \vee m(A, x \mid \boldsymbol{N H Y}) \\
m(A, x \mid \boldsymbol{C B D})=\vee\{[V(P(x, A), W) \wedge S(W)], W \in \boldsymbol{C B} \boldsymbol{D}\} \text { - epistemic, modal L-fuzzy membership function; } \\
m\left(A, x \mid \boldsymbol{C}^{\prime} \boldsymbol{G T}\right)=\vee\left\{[V(P(x, A), W) \wedge S(W)], W \in \boldsymbol{C}^{\prime} \boldsymbol{G} \boldsymbol{T}\right\} \text { - deontic, doxastic L-fuzzy membership function; } \\
m(A, x \mid \boldsymbol{N H Y})=\vee\{[V(P(x, A), W) \wedge S(W)], W \in \boldsymbol{N H Y}\} \text { - dynamic logic L-fuzzy membership function. }
\end{gathered}
$$

We can follow the general process from [5, 6] based on Kripke possible worlds semantics to define intersection and unions of Kabbalistic L-fuzzy sets using the above calculation of the membership function based on our Kabbalah semantic frame of possible worlds $\langle W, R>=T$ (Ban, Mah)with world weighting function $S$ and using the lattice $L$ instead of $[0,1]$. For two Kabbalistic L-fuzzy sets, $A$ and $B$, described by membership 
functions $m(A, x)$ and $m(B, x)$ constructed above, their union $A \cup B$ and intersection $A \cap B$ have membership functions defined as follows for the simpler case when $V:$ Prop $\times W \rightarrow\{0,1\}$ and $W=T($ Ban, Mah):

$$
\begin{gathered}
m(A, \cdot): X \rightarrow L, m(B, \cdot): X \rightarrow L, S: W \rightarrow L \\
m(A \cup B, x)=\vee\{[S(W(k))] \text { for all } k \text { such that either } V(P(x, A), W(k))=1 \text { or } V(P(x, B), W(k))=1\} \\
m(A \cap B, x)=\vee\{[S(W(l))] \text { for all } l \text { such that both } V(P(x, A), W(l))=1 \text { and } V(P(x, B), W(l))=1\} .
\end{gathered}
$$

\section{Conclusion}

We built a Kabbalah fractal multiple valued modal logic and Kabbalah semantic foundation for a postmodern fuzzy set and fuzzy logic theory. We focused here on the modal semantic frame model construction and we did not elaborate a proper axiom system for properly defined modal operators. The cognitive, emotional and behavioral levels of the Kabbalah frame correspond to the epistemic and modal, doxastic and deontic etc. modal logics. We defined constructively Kabbalistic L-fuzzy sets based on a Kripke type of Kabbalah possible worlds frame. We showed recently [15]-[17] how Kabbalah can be used to develop postmodern versions of knowledge engineering and knowledge based systems, of humanistic system cybernetics and humanistic system theory and of behavioral finance and economics. The Kabbalistic L-fuzzy set concept and the Kabbalah semantic frame for the fractal multi-modal Kabbalah logic can be applied via the frameworks introduced in [15]-[17] to knowledge engineering, cybernetics, behavioral finance and economics for humanistic systems.

\section{Acknowledgements}

G.B. would like to express his gratitude to R. Dangur, A. Babayove, M. Kranz, M. Millstein, M. Handler, N. Citron for their mentoring and teachings and to A. Sutton, S. Anteby, A. Greenbaum, E. Goldstein, Y. Ginsburgh, M. Laitman, E. Yardeni and D. Pinson for their insightful lectures. We thank M. Schatz for a discussion on his work. Authors thank Tian Huang from Applied Mathematics (AM) journal Editorial Office for her patient and resourceful assistance in our preparing and submitting this paper to AM Fuzzy Mathematics special issue.

\section{References}

[1] Zadeh, L.A. (1965) Fuzzy Sets. Information and Control, 8, 338-353. http://dx.doi.org/10.1016/S0019-9958(65)90241-X

[2] Negoita, C.V. and Ralescu, D.A. (1975) Applications of Fuzzy Sets to Systems Analysis. John Wiley \& Sons, New York. http://dx.doi.org/10.1007/978-3-0348-5921-9

[3] Goguen, J.A. (1967) L-Fuzzy Sets. Journal of Mathematical Analysis and Applications, 18, 145-174. http://dx.doi.org/10.1016/0022-247X(67)90189-8

[4] Dubois, D. and Prade, H. (2006) Possibility Theory and Its Applications: A Retrospective and Prospective View. Decision Theory and Multi-Agent Planning, CISM International Centre for Mechanical Sciences, 482, 89-109. http://dx.doi.org/10.1007/3-211-38167-8 6

[5] Resconi, G., Klir, G.J. and St. Clair, U. (1992) Hierarchical Uncertainty Metatheory Based upon Modal Logic. International Journal of General Systems, 21, 23-50. http://dx.doi.org/10.1080/03081079208945051

[6] Turksen, I.B. (2006) An Ontological and Epistemological Perspective of Fuzzy Set Theory. Elsevier, Amsterdam.

[7] Dubois, D. and Prade, H. (1997) The Three Semantics of Fuzzy Sets. Fuzzy Sets and Systems, 90, 141-150. http://dx.doi.org/10.1016/S0165-0114(97)00080-8

[8] Negoita, C.V. (2002) Postmodernism, Cybernetics and Fuzzy Set Theory. Kybernetes, 31, 1043-1049. http://dx.doi.org/10.1108/03684920210436327

[9] Menzi, D.W. and Padeh, Z. (2008) The Tree of Life: Chayyim Vital's Introduction to the Kabbalah of Isaac Luria. Arizal Publications Inc., New York.

[10] Afilalo, R. (2004) The Kabbalah of the Arizal According to the Ramhal. Kabbalah Editions, Montreal.

[11] Luzzatto, M.C. (2005) 138 Openings of Wisdom. Azamra Institute, Jerusalem.

[12] Cresswell, M.J. and Hughes, G.E. (1996) A New Introduction to Modal Logic. Routledge, London. 
[13] Schatz, M. (2002) Tikkun Leil Shavuot (In Hebrew). Mechon Pitchey Migadim, Jerusalem.

[14] Zadeh, L.A. (1971) Quantitative Fuzzy Semantics. Information Sciences, 3, 159-176. http://dx.doi.org/10.1016/S0020-0255(71)80004-X

[15] Burstein, G. and Negoita, C.V. (2014) A Kabbalah System Theory Modeling Framework for Knowledge Based Behavioral Economics and Finance. In: Mago, V.K. and Dabbaghian, V., Eds., Computational Models of Complex Systems, Intelligent Systems Reference Library 53, Springer International Publishing, Switzerland, 5-23. http://dx.doi.org/10.1007/978-3-319-01285-8_2

[16] Burstein, G. and Negoita, C.V. (2013) A Kabbalah System Theory of Ontological and Knowledge Engineering for Knowledge Based Systems. International Journal of Advanced Research in Artificial Intelligence, 2, 9-14. http://dx.doi.org/10.14569/IJARAI.2013.020202

[17] Burstein, G. and Negoita, C.V. (2011) Foundations of a Postmodern Cybernetics Based on Kabbalah. Kybernetes, 40, 1331-1352. http://dx.doi.org/10.1108/03684921111169422 